\title{
Tingkat Stres Perawat di RSUD Bima Nusa Tenggara Barat Sebelum dan Setelah Safety Morning Talk
}

\author{
Rita Kartika Syarif ${ }^{1}$, Yuliani Setyaningsih ${ }^{2}$, Muhammad Zen Rahfiluddin ${ }^{3}$ \\ ${ }^{1,2,3}$ Universitas Diponegoro, Semarang \\ *Email:ritakartika966@gmail.com
}

\begin{abstract}
Nurse work stress is an important issue in third world countries. Working with the pressure of a deadline, having an excessive workload is also a process that stimulates stress due to work. Special communication between the head of the room and the nursing nurse will be a conducive atmosphere to reduce work stress. One type of communication can be in the form of safety morning talk with the theme of work stress therapy with the help of a guidebook media. The purpose of this study was to determine the impact of safety morning talk on the level of work stress on nurses in Bima Hospital before and after treatment, with the type of research that is the quasi experiment design conducted in February - April 2019. The population in this study were nurses in the surgical treatment room and treatment room internal diseases which amounted to 35 respondents using total sampling techniques. The measuring instrument used is the Nurse Stress Scale questionnaire. The results of this study indicate that there is an effect of safety morning talk in reducing nurses' work stress in Bima Hospital ( $p$ value <0.05).
\end{abstract}

Keywords :Safety Morning Talk, Job Stress , Nurse Stress

\begin{abstract}
Abstrak
Stres kerja perawat merupakan isu yang penting di negara-negara dunia ketiga. Bekerja dengan tekanan batas waktu, memiliki beban kerja yang berlebih juga merupakan proses yang merangsang terjadinya stres akibat kerja. Komunikasi yang khusus yang dilakukan antara kepala ruangan dan perawat pelaksana akan menjadi suasana yang kondusif untuk mengurangi stres kerja. Salah satu jenis komunikasinya bisa dalam bentuk safety morning talk bertema terapi stres kerja dengan bantuan media buku panduan. Tujuan penelitian ini untuk mengetahui dampak safety morning talk terhadap tingkat stres kerja pada perawat Rumah Sakit Umum Daerah Bima sebelum dan setelah perlakuan, dengan jenis penelitian yaitu rancangan quasi experiment yang dilakukan pada Februari - April 2019. Populasi dalam penelitian ini adalah perawat pelaksana di ruang perawatan bedah dan ruang perawatan penyakit dalam Rumah Sakit Umum Daerah Bima yang berjumlah 35 responden dengan menggunakan teknik total sampling. Alat ukur yang digunakan yaitu kuesioner Nurse Stress Scale disingkat NSS. Hasil Penelitian ini menunjukkan ada pengaruh safety morning talk dalam menurunkan stres kerja perawat RSUD Bima (nilai $\mathrm{p}<0,05)$.
\end{abstract}

Kata kunci :Safety Morning Talk, Stres Kerja, Stres Perawat

\section{Pendahuluan}

Safety Morning Talk merupakan komunikasi yang dilakukan selama lima sampai sepuluh menit sebelum melakukan pekerjaan di pagi hari[1]. Komunikasi juga merupakan salah satu faktor yang dapat mengurangi stres pada perawat, yang umumnya hanya fokus pada kecelakaan medis yang berkaitan dengan tugas-tugas mereka[2], [3]. Stres kerja merupakan masalah yang sangat penting sebab terkait dengan produktifitas kerja karyawan[4]. Banyak penelitian dilakukan untuk mencari hubungan antara stres kerja dengan berbagai penyakit, stres memainkan peran terutama pada penyakit kardiovaskular, gangguan muskuloskeletal, dan gangguan psikologis[5].

Profesi perawat juga merupakan pekerjaan yang dapat menyebabkan stres. Tingginya tingkat stres perawat sering 
mengarah pada distress moral, yakni gangguan yang terjadi ketika orang percaya bahwa mereka tahu hal yang benar untuk dilakukan tapi tak mampu melakukan tindakan atau keputusan moral[6], [7]. Oleh karena itu, stres akibat kerja disarankan untuk lebih diperhatikan, agar komitmen dan keberhasilan pekerjaan semakin kuat[8]. Temuan dari penelitian di Nigeria menunjukkan bahwa beban kerja adalah hal yang menempati peringkat pertama yang menghasilkan frekuensi tertinggi dari stres kerja perawat[9]. Di Perancis, stres yang dialami perawat yaitu sebesar $74 \%$ dan Swedia lebih dari $80 \%$ perawat mengalami stres berat akibat pekerjaan[10]. Di Eropa, 30\% dari perawat yang disurvei melaporkan kelelahan karena aktivitas kerja. Di Inggris, sekitar $42 \%$ dari perawat dilaporkan menderita burnout, di Yunani sekitar $44 \%$ dari perawat mengalami perasaan ketidakpuasan di tempat kerja dan keinginan untuk meninggalkan pekerjaan[11].

Sekitar 50,9\% perawat yang bekerja di empat provinsi di Indonesia mengalami stres kerja. Perawat sering mengalami pusing dan, kelelahan, karena beban kerja yang tinggi. Hal tersebut menyebabkan ketidakhadiran meningkat, menurunnya produktivitas sehingga berdampak pada penurunan mutu pelayanan di rumah sakit[12].

Dari hasil observasi peneliti pada Juni tahun 2018, terdapat tujuh rumah sakit yang ada di Bima, salah satunya adalah Rumah Sakit Umum Daerah Bima (RSUD Bima) dan angka kunjungannya paling tinggi dibanding enam rumah sakit lainnya. Dari wawancara terhadap $11 \%$ perawat yang ada di Ruang Perawatan Penyakit Dalam dan $15 \%$ perawat Ruang Perawatan Bedah didapatkan hasil, bahwa selama bekerja perawat merasakan stres saat bekerja akibat suara penunggu pasien yang keras, komplain dengan nada keras, keluarga pasien yang kurang kooperatif, harapan tinggi dari keluarga pasien, risiko penularan penyakit, kematian pasien, pasien kurang kooperatif, ruangan yang kecil, keluarga pasien yang ramai, serta keluarga pasien yang panik.
Penelitian ini bertujuan untuk mengetahui pengaruh dari safety morning talk dalam menurunkan tingkat stres kerja perawat di RSUD Bima. Peneliti menyadari akan pentingnya peranan perawat bagi produktifitas pelayanan di Rumah Sakit Umum DaerahBima oleh karena itu peneliti menganggap sangat perlu untuk melakukan penelitian yang menganalisis tingkat stres kerja pada perawat di RSUD Bima.

\section{Metoda Penelitian}

\subsection{Tahapan Proses Pengembangan MediaBuku Panduan Praktis Terapi Stres Kerja}

Peneliti melakukan survei pendahuluan tentang evidence based terkait stres kerja pada perawat di RSUD Bima. Kemudian dilanjutkan dengan wawancara terstruktur kepada 20 orang perawat di bulan Juni 2018 apakah dalam 6 bulan terakhir mereka pernah mendapatkan pelatihan atau briefing tentang manajemen stres, jika pernah berapa kali, mengenai apa, siapa yang menyampaikan, cara penyampaian penyuluhan, alat bantu yang digunakan dan pendapat mereka mengenai cara promosi kesehatan serta alat bantu yang menarik. Sehingga sampai pada kesimpulan bahwa perlu adanya safety morning talk melalui media buku panduan praktis terapi stres kerja yang disusun oleh peneliti sendiri. Kemudian setelah itu dilakukan pre-testing media dimaksudkan untuk menentukan unsurunsur mana dari suatu media yang perlu dirubah agar komunikasi lebih efektif, mudah dipahami, bisa diterima dari segi sosial budaya sasaran sebelum disebarluaskan. Sasaran pelaksanaan pre-testing media adalah responden yang memiliki karakteristik hampir sama dengan sampel penelitian, yang bukan menjadi bagian kelompok eksperimen dan kelompok kontrol. Hasil dari pre-testing akan dijadikan acuan untuk memperbaiki media sehingga dapat lebih menarik, mudah dipahami, persuasif informatif, dan dapat diterima sasaran. Berikut adalah alur pembuatan media buku panduan praktis terapi stres kerja (Gambar 1). 


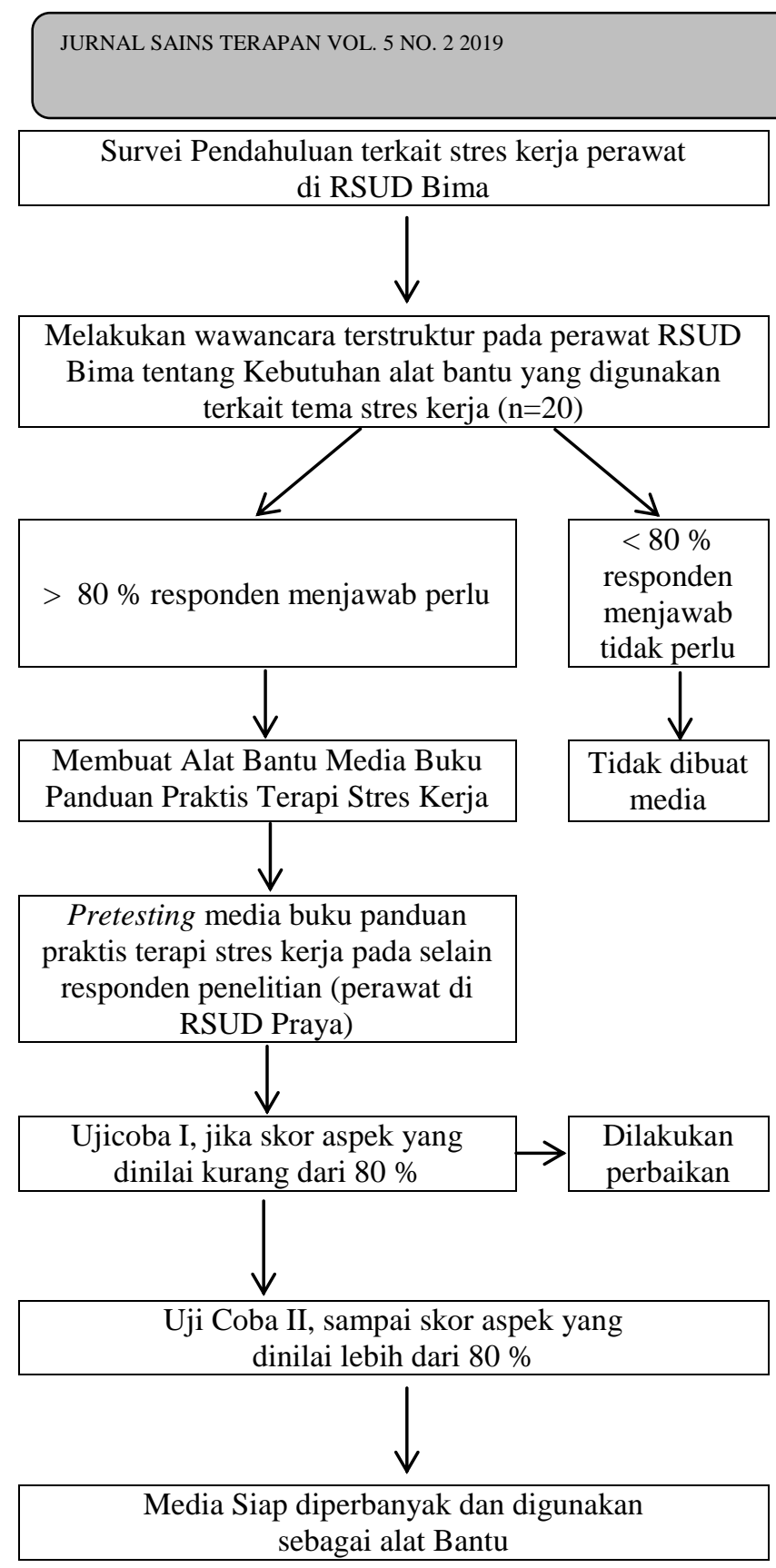

Gambar 1. Alur Pembuatan Media Buku Panduan Praktis Terapi Stres Kerja

\subsection{Sumber Data}

Sumber data dalam penelitian ini diperoleh melalui kuesioner Nurse Stress Scale (NSS) untuk mengukur tingkat stres kerja dari perawat pelaksana di ruang perawatan bedah dan ruang perawatan penyakit dalamsebelum dan sesudah dilakukan intervensi safety morning talk. Kuesioner tersebut terdiri dari 34 item pertanyaan dengan 7 faktor yang mempengaruhi suasana pada unit rumah sakit sebagai pemicu terjadinya stres kerja. 
Berdasarkan hasil penelitian karakteristik responden berdasarkan umur, pendidikan, masa kerja, lama tidur per hari, status gizi, kebiasaan berolahraga, dan sumber informasi lainnya tentang terapi stres kerja dapat dilihat pada Tabel 1 .

Tabel 1. Distribusi Responden Penelitian

\begin{tabular}{lcc}
\hline \multicolumn{1}{c}{ Atribut } & Frekuensi & Prosentase (\%) \\
\hline Umur & & \\
\hline 1. Dewasa Awal & 7 & 20 \\
\hline 2. Dewasa Akhir & 28 & 80 \\
\hline Pendidikan & & \\
\hline 1. D3 & 10 & 74,3 \\
\hline 2. D4 & 7 & 11,4 \\
\hline 3. S1 & 18 & 14,3 \\
\hline Masa Kerja & & \\
\hline 1. $\leq 15$ Tahun & 1 & 2,9 \\
\hline 2. 15 tahun & 34 & 9,7 \\
\hline Lama tidur Per Hari & & \\
\hline 1. 6 jam & 10 & 28,6 \\
\hline 2. 7 jam & 12 & 34,3 \\
\hline 3. 8 jam & 13 & 37,1 \\
\hline Status Gizi & & \\
\hline 1. Normal & 18 & 51,4 \\
\hline 2. Obes Tk I & 16 & 45,7 \\
\hline 3. Obes Tk II & 1 & 2,9 \\
\hline Kebiasaan Olah Raga & & \\
\hline 1. Tidak Pernah & 7 & 20 \\
\hline 2. 1 x per minggu & 26 & 74,3 \\
\hline 3.>1 x per minggu & 2 & 5,7 \\
\hline Sumber Informasi lainnya tentang terapi stres & \\
\hline 1. Media Elektronik & 25 & 71,4 \\
\hline 2.Media Cetak & 8 & 22,9 \\
\hline 3.Orang Lain & 2 & 5,7 \\
\hline & & \\
\hline
\end{tabular}

\subsection{Analisis Statistik Deskriptif}

Analisis statistik deskriptif dilakukan untuk mengetahui gambaran tingkat stres responden pada perawat di RSUD Bima. Gambaran deskriptif ini mencakup sebelum dan sesudah dilakukan intervensi safety morning talk. Hasil analisis deskriptif tingkat stres perawat di RSUD Bima sebelum dilakukan intervensi terlihat pada Tabel 2 .

Tabel 2 menunjukkan bahwa sebagian besar kategoritingkatstreskerja perawat di RSUD Bima sebelum dilakukan intervensi safety morning talk masih dalam kategori stres ringan.Temuan ini bermakna bahwa perawat sudah mengalami stres kerja meski dalam kategori sedang. Namun perolehan ini diharapkan dapat kurangi atau diturunkan setelah perawat diberikan safety morning talk melalui media buku panduab praktis terapi stres kerja.

Tabel 2. Deskripsi Tingkat Stres Kerja Sebelum Intervensi

\begin{tabular}{|c|c|}
\hline Kategori Stres Kerja & Frekuensi (\%) \\
\hline Ringan & - \\
\hline Sedang & 85,7 \\
\hline Berat & 14,3 \\
\hline Total & 100 \\
\hline Mean & 49,20 \\
\hline
\end{tabular}

Sementara itu, pada Tabel 3 menggambarkan tingkat stres perawat setelah dilakukan safety morning talk dinilai masih hampir sama. Namun jika dibandingkan dengan sebelum dilakukan intervensi, perolehan nilai rata-rata pada tingkat stres kerja mengalami penurunan. Artinya, safety morning talk mampu menurunkan tingkat stres kerja perawat di RSUD Bima.

Tabel 3. Deskripsi Tingkat Stres Perawat Setelah Intervensi

\begin{tabular}{lc}
\multicolumn{1}{c}{ Kategori stres Kerja } & Frekuensi $(\%)$ \\
\hline \multicolumn{1}{l}{ Ringan } & 62,9 \\
\hline Sedang & 37,1 \\
\hline Berat & 0 \\
\hline \multicolumn{2}{c}{ Total } \\
\hline Mean & 100 \\
\hline & 25,83 \\
\hline
\end{tabular}

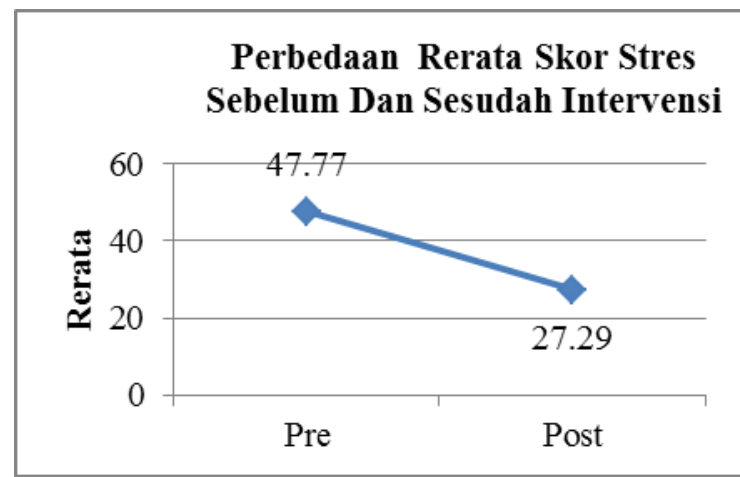

Gambar 2. Grafik Penurunan Stres Kerja saat Pre-Test dan Post-Test 


\subsection{Pembahasan}

Hasil penelitian ini juga menjelaskan perbedaan rerata tingkat stres kerja responden pada kelompok intervensi sebelum dan setelah perlakuan (Tabel 2 dan Tabel 3). Rerata tingkat stres responden mengalami penurunan, ini berarti ada pengaruh intervensi safety morning talk dengan media buku panduan praktis terapi stres kerja. Analisis perbedaan dengan uji wilcoxon juga mendapatkan nilai $\mathrm{p}<0,05$ yang artinya ada perbedaan bermakna antara stres kerja sebelum dan setelah intervensi. Dengan kata lain, ada pengaruh intervensi safety morning talk dengan media buku panduan praktis terapi stres kerja.

Penelitian sebelumnya yang relevan tentang pengaruh komunikasi terhadap stres kerja juga pernah diteliti dengan hasil bahwa ada pengaruh komunikasi terhadap stres kerja perawat[3]. Komunikasi juga merupakan salah satu cara pendidikan kesehatan yang bisa meningkatkan pemahaman dan self-care pada perawat dan bisa berupa safety morning talk khususnya tentang terapi stres kerja perawat [14].

Safety morning talk juga merupakan salah satu upayauntuk menjadikan komunikasi sebagai salah satu cara untuk menghindari terjadinya moral distress pada perawat [7]. Menurut teori difusi-inovasi Rogers menyatakan bahwa komunikasi juga bisa membantu menurunkan stres pada manusia [15].

\section{Saran}

Perlu adanya pelatihan manajemen stres yang berfokus pada topik yang didasarkan pada konteks yang diidentifikasi oleh peserta sehingga dapat mengoptimalkan komunikasi antara perawat rumah sakit, pasien dan perawat.

Selalu melatih dan mempraktikan terapi stres kerja sehingga dapat mengurangi stres akibat pekerjaan yang tentunya akan mampu mengoptimalkan performance dan produktifitas kerja perawat.

\section{Daftar Pustaka}

[1] R. Marliani, Psikologi Industri \& Organisasi. Bandung: CV Pustaka Setia, 2015.

[2] K. Kunie, N. Kawakami, A. Shimazu, Y. Yonekura, and Y. Miyamoto, "The relationship between work engagement and psychological distress of hospital nurses and the perceived communication behaviors of their nurse managers: A cross-sectional survey,” Int. J. Nurs. Stud., 2017.

[3] K. O. Park, S. H. Park, and M. Yu, "Physicians' Experience of Communication with Nurses related to Patient Safety: A Phenomenological Study Using the Colaizzi Method," Asian Nurs. Res. (Korean. Soc. Nurs. Sci)., 2018.

[4] C. D. Sucipto, Keselamatan dan Kesehatan Kerja. Gosyen Publishing, 2014.

[5] Niosh, "Stress At Work," Natl. Inst. Occup. Saf. Heal., 1999.

[6] H. I. G. H. N. S. Ettings, B. Cynda, H. Rushton, and J. Batcheller, "Burnout and Resilence Among Nurses Practicing in HighIntensity Settings," 2015.

[7] P. B. Whitehead, R. K. Herbertson, A. B. Hamric, E. G. Epstein, and J. M. Fisher, "Moral Distress Among Healthcare Professionals: Report of an Institution-Wide Survey,” J. Nurs. Scholarsh., 2015.

[8] M. Eskandari and M. A. Heidari Gorji, "Can Work-Related Stress And Job Satisfaction Affect Job Commitment Among Nurses? A Cross-Sectional Study," F1000Research, 2018.

[9] F. A. Faremi, M. I. Olatubi, K. G. Adeniyi, and O. R. Salau, "Assessment of occupational related stress among nurses in two selected hospitals in a city southwestern Nigeria," Int. J. Africa Nurs. Sci., 2019.

[10] I. Sumarto, P. Asfian, S. Munandar, and U. H. Oleo, "Perbedaan Stress Kerja ditinjau dari Shift Kerja Pagi Siang dan Malam pada Perawat di Rumah Sakit Umum Daerah Kota Kendari," 2016.

[11] V. F. Ribeiro et al., "Prevalence Of Burnout Syndrome In Clinical Nurses At A Hospital Of Excellence," Int. Arch. Med., 2014.

[12] S. D. Sasanti and Z. Shaluhiyah, "Personality Berpengaruh terhadap Terjadinya Stress Kerja Perawat di Ruang Rawat Inap Rumah Sakit Umum Kota Salatiga,” 2016.

[13] RSUD Bima, Profil RSUD Bima. 2016.

[14] N. Y1ldırım, A. Karaca, S. Cangur, F. 
Ac1kgoz, and D. Akkus, "The relationship between educational stress, stress coping, selfesteem, social support, and health status among nursing students in Turkey: A structural equation modeling approach," Nurse Educ. Today, 2017.

[15] J. B. Ellsworth, “The Innovation - Rogers' Diffusion of Innovations," Surviving Change A Survey of Educational Change Models. 2000. 